\title{
NON-CHOLINERGIC, EXCITATORY JUNCTION POTENTIALS IN SMOOTH MUSCLE OF CHICKEN RECTLM
}

\author{
Hidenori OHASHI, Kyozo NAITO. Tadashi TAKEWAKI \\ and Toshiaki OKADA \\ Deparment of Pharmacologl, Faculty of Agriculnwe, Gifu University. \\ Kahamisahara, Gifn 504. Japan
}

Accopert Iscomber 8.1976

\begin{abstract}
Ibstract - Muscle strips from the longitudinal or circular muscle of the chicken rectum twe used to determine changes in membranc potential during field stimulation as recorded using the sucrose-gap method. Stimulation with single square pulses $(0.1$ msce duration) evoked junction potentials elicited by transmitter relcased from nerve endings. Facilitation in amplitude of excitatory junction potentials (F.JPs) was secn during repetitive stimulation in the longitudinal muscle, but in the circular muscle, FJPs reduced. Neither atropine nor hyoscine (up $1010^{-3} \mathrm{~g} \mathrm{ml}$ ) reduced EJPs. These drugs abolished the depression of EJPs in the circular muscle produced by repetilive stimulation. Anticholinesterases $\left(2 \quad 10^{*}-2 \quad 10^{\circ} \mathrm{g} \mathrm{ml}\right.$ ) reduced the EJPs. The inhibitory effect was produced without allecting the membrane resistance of smooth muscle and was completely antagonized by atropine $(10 " \mathrm{~g} \mathrm{ml})$. Drugs that abolish the adrenergic functions did not affect the EJPs. These results suggest that nerves insolved in the EJPs are non-cholinergic and non-adrenergic in nature, and the motor transmission to the smooth muscle may be inhibited by cholinergic nerves, presumably press naptically:
\end{abstract}

In at previous paper (1) we demonstrated that the rectal muscle in the chicken has excitatory and inhibitory innervations via the Remak's nerve, so that the muscle shous a biphasic response, contraction followed by relaxation, in response to the Remak is nerve stimulation and also to transmural stimulation. Furthermore, we considered that the nerve stimulation produced contraction due to activity of motor nerves releasing an unk nown Iransmitter, since the contractile component of the response remains almost unaltered after treatment with drugs which reduce cholinergic and adrenergic activities.

In intestinal smooth muscle, acetylcholine or stimulation of cholinergie nerves causes depolarization. enhances spike frequency and so produces contraction. The present experiments were undertaken to determine whether contraction of the rectal muscle in response 10 nerve stimulation uas similarly hased on depolarization and initiation of spike potentials and to study neurotransmission to the longitudinal and circular muscle layers.

Part of this data was presented at the 49 th Cieneral Veeting of Japanese Pharmacologica! Society (2).

\section{MATERIALS AND METHODS}

Adult chickens of either sex were bled and the whole rectum was exposed, isolated, ectioned lengthwise and pinned serosal side up on a rubber board. Strips. about $30 \mathrm{~mm}$ 
in length and $0.5 \mathrm{~mm}$ in width, were cut away along either the longitudinal muscle or circular muscle from the wall of each rectum, in which the tissues other than the muscle layer were carefully detached under a binocular microscope. They were set up in a sucrose-gap apparatus similar to that used by Bülbring \& Burnstock (3) for extracellular measurement of the membrane potential change. A pair of $\mathrm{Ag}-\mathrm{AgCl}$ electrodes for recording the membrane potential were connected to a pair of cathode followers and the potential was amplified by a $\mathrm{DC}$ amplifier and recorded on a pen-oscillograph. Another pair of $\mathrm{Ag}-\mathrm{AgCl}$ ring electrodes for field stimulation of the intramural nerves was embedded in the vertical polyethylene lube of the sucrose-gap apparatus, through which flowed Tyrode solution. Stimuli could be given across the one end of the strip $4 \mathrm{~mm}$ apart from the recording electrode. The field stimulation was effected by an electronic stimulator (Nihon Khoden). The duration of pulse stimuli was fixed at $0.1 \mathrm{msec}$ and the stimulus intensity producing submaximal responses was selected. Mechanical changes of the strip were transmitted by an isometric mechanoelectronic transducer (Nihon Khoden) connected with a fine thread to the end of the preparation suspended in Tyrode solution, and recorded simultaneously with a membrane potential change. In a limited number of experiments, the strip was mounted in a double sucrose-gap apparatus, as described by Bülbring \& Tomita (4). Electrotonic potentials were evoked by current pulses with 1 sec duration and effects of drugs were observed in order to determine the action on the membrane conductance.

Tyrode solution (composition, $\mathrm{mM}$ : $\mathrm{NaCl} 137.0 ; \mathrm{KCl} 2.7 ; \mathrm{NaH}_{2} \mathrm{PO}_{4} 0.4 ; \mathrm{NaHCO}_{3}$ $12.0 ; \mathrm{MgCl}_{2} 1.0 ; \mathrm{CaCl}_{2} 1.8 ;$ Glucose 5.0 ) was aerated and kept at $35^{\circ} \mathrm{C}$.

The drugs used were tetrodotoxin (Sankyo), hexamethonium bromide ( $K \& \mathrm{~K}$ ), d-tubocurarine chloride (Sigma), atropine sulfate (Tanabe), hyoscine hydrobromide (Wako), acetylcholine chloride (Tokyo Kasei), physostigmine salicylate (Merck), neostigmine bromide (Sigma), DFP (Sigma), phentolamine mesylate (Ciba) and guancthidine sulfate (Ciba).

The maximum amplitude of the junction potentials and electrotonic potentials were measured from the recording base lines. The latency of the junction potentials was measured from the stimulus artefact to the initiation of the transient and the duration from onset to the end of the depolarization. No allowances were made for possible errors resulting from the pen recorder.

\section{RLSULTS}

\section{Electrical responses to field stimulation}

Preparations with little spontaneous activity permitted observation of electrical responses to field stimulation. Stimulation with single square pulses elicited a small and transient depolarization. Depolarization followed by a hyperpolarization was rare in longitudinal muscle strips (in 5 out of 54) and very occasional in circular muscle strips (in 32 out of 35 ). as illustrated in Fig. 1. As the stimulus intensity was progressively increased, the size and the rate of the electrical response increased until the amplitude of depolarization reached a threshold for initiation of the action potential.

conversions from a monophasic response to a biphasic one or in the opposite direction 

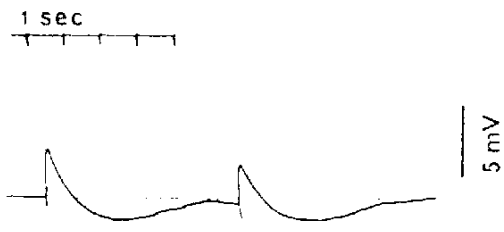

Fici. 1. Electrical responses of circular muscle on stimulating the intramural nerves. Lpper short trace time marker: lower trace, membrane potential recording. Original level of the membrane potential is indicated by the broken line. Vote the hyperpolarization after each depolarizing response.

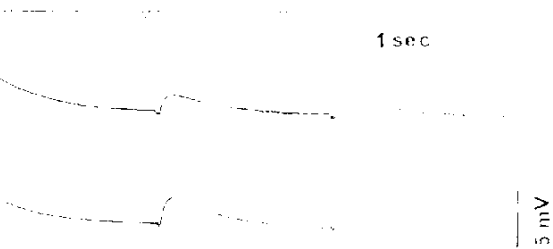

HK. 2. Tine course of EJPs evolied by stimulation of the intramural nerves in the circular and longitudinal muscles. Top trace, time marker; middle, circular muscle; bottom, longitudinal muscle.

were not observed with change in the stimulus intensity. Response to field stimulation was absent in the presence of TTX $\left(10^{-i} \mathrm{~g} / \mathrm{ml}\right)$ in the perfusion fluid. Depolarization and hyperpolarization were apparently neurally mediated and thus were interpreted to be junction potentials elicited by transmitters released from nerve endings.

In the longitudinal muscle, the maximum depolarization was $8 \mathrm{~m} \vee$ and usually less than $5 \mathrm{mV}$. The latency to the onset of depolarization varied from 15 to $25 \mathrm{msec}$ with a mean of $18.5 \pm 0.8 \mathrm{msec}(\mathrm{n}=22)$. The peak depolarization was reached between 68 and $180 \mathrm{msec}$ with a mean of $114.5+8.5 \mathrm{msec}(\mathrm{n}=-22$ ). Complete decay of the response occurred from 610 to $1400 \mathrm{msec}$ with a mean of $1020 \pm 40 \mathrm{msec}(\mathrm{n}=22)$. Measurements were also made of the latency and the time required to reach a maximum height of E.JPs recorded in 18 strips from the circular muscle. The mean values were not significantly different from those of EJPs in the longitudinal muscle. Fig. 2 represents EJPs recorded from both circular and longitudinal muscle strips. In the total number of 40 preparations, the mean latency was $17.7 \pm 0.6 \mathrm{msec}$ and the mean time to the peak depolarization was $115.0 \pm 6.8 \mathrm{msec}$. Since EJPs in the circular muscle usually led to a falling phase of inhibitory junction potentials (IJPs), the duration of the EJPs could not be measured. The JIP reached maximum hyperpolarization from 1300 to $2300 \mathrm{msec}$ and up to $3 \mathrm{mV}$. Complete recovery was seen in 2.7 to $4.6 \mathrm{sec}$.

Repetitive stimulation at frequencies between 0.4 and $0.8 \mathrm{~Hz}$ produced discrele EJPs. Facilitation was seen in the longitudinal muscle with a gradual increase in amplitude, as shown in Fig. 3a. When the amplitude of depolarization reached the firing level, a spike potential was initiated. At frequencies up to $4 \mathrm{H}$, successive, summed EJPs caused it sustained membranc depolarization. In contrast, facilitation was never observed on the EJPs in the circular muscle, rather the peak depolarization became much smaller in the second EJP than in the first and the same magnitude of depression was seen in all subsequently elicited EJPs. Such depolarization illustrated for EJPs evoked at a frequency of $0.8 \mathrm{~Hz}$ is shown in Fig. 3b. In the majority of the longitudinal muscle strips and in all the circular muscle strips, a sustained membrane hyperpolariation developed during repetitive stimu- 


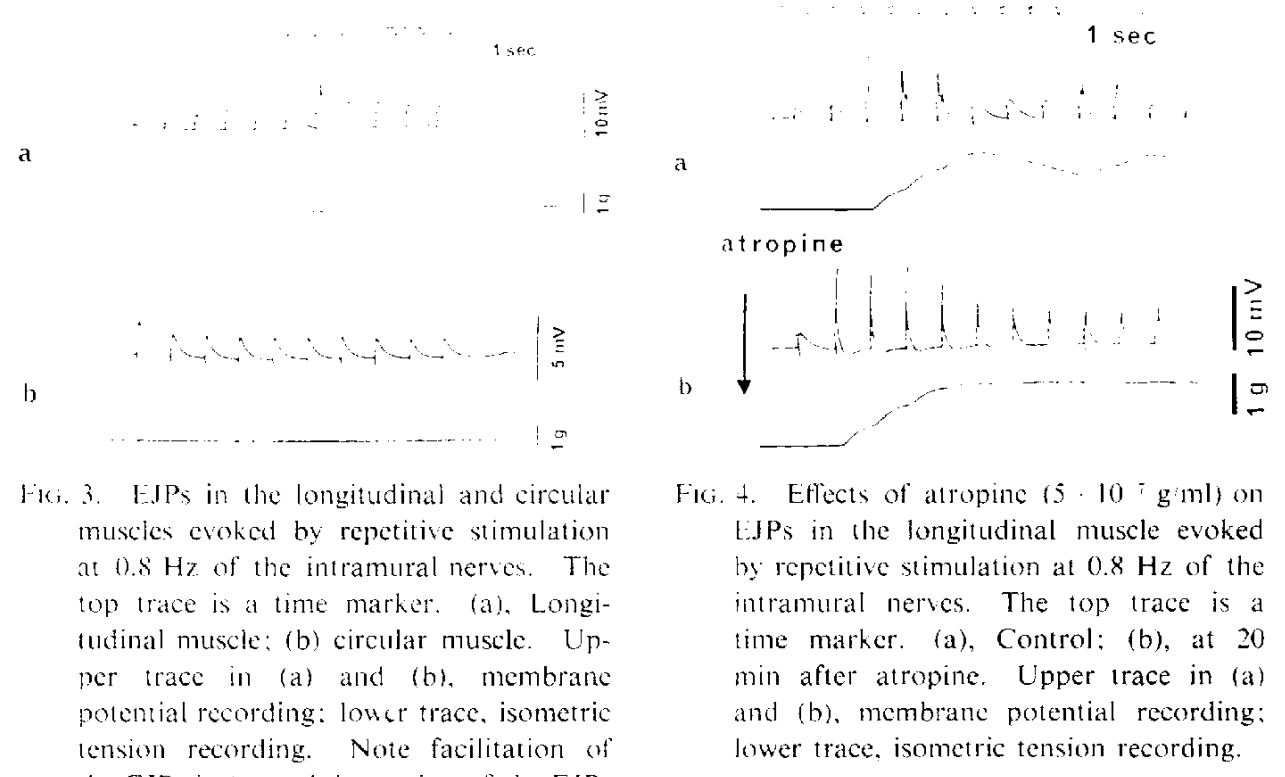

lation at frequencies between 0.4 and $0.8 \mathrm{H} \%$, the nragnitude of which was independent of the stimulus frequency but varied between preparations. This hyperpolarization decayed with a time course similar to that of the IJP after cessation of the stimulation.

Effects of diugs on EJPS

EJl's were croked by trains of 10 to 20 pulses at a frequency of $0.8 \mathrm{~Hz}$. The trains were delivered at an interval of about 5 min. Hexamethonium, added to the perfusion Puid to give concentrations up to $10^{-4} \mathrm{~g} / \mathrm{ml}$, had no effect on the EJPs ( 3 experiments). d-Tubocularine (up to $510^{-5} \mathrm{~g} \mathrm{ml}$ ) also had no effect on the potentials. These results indicate that the intramural motor nerves stimulated are postganglionic and that the EJPs are not mediated through activation of the nicotinic receptors on the rectal muscle. Atropine or hyoscine in a concentration of $10^{-}-\mathrm{g} / \mathrm{nl}$ abolished the depolarizing effect of exogenously applicd acetylcholine $\left(10^{-6} \mathrm{~g} / \mathrm{ml}\right)$ on the smooth muscle, but did not inhibit the EJPs. These drugs did not reduce the EJPs even when the concentration was cumulatively increased up to $10^{-5} \mathrm{gml}$ ( 8 experiments), however, a significant increase in amplitude of the EJPs was cvident. Fig. 4 illustrates EJPs with or without spikes in the longitudinal muscle evoked before and after application of atropine (5 $10^{--} \mathrm{g} / \mathrm{ml}$ ). EJPs are appreciably larger in the presence of atropine and more effective in initiating spikes. Atropine and hyoscine also attenuated sudden decrenents in amplitude of EJPs in the circular muscle during repetitive stimulation. This occurred with little or no changes in the sustained hyperpolarization. In some preparations, weak facilitation was seen in the E.JPs in the presence of these drugs. as shown in Fig. 5. Physostignine in concentrations of $2 \quad 10^{-x}$ to $2 \times 10^{-6} \mathrm{~g} / \mathrm{ml}$ resulted in dose-dependent decreases in FIPs and the uppermost concentration of this drug abolished 


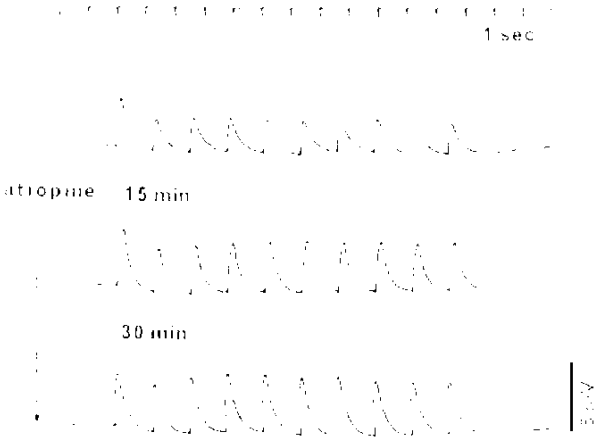

Fici. 5. Fifects of atropine $\left(10^{-} \mathrm{g}\right.$ gml $)$ on LJPs in the circular muscle evoked by repetitive stimulation at $0.8 \mathrm{~Hz}$ of the intramural nerves. Top trace, time marker: second, control; third and bottom, at 15 and $30 \mathrm{~min}$ after atropine.

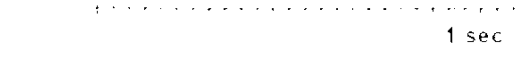

a
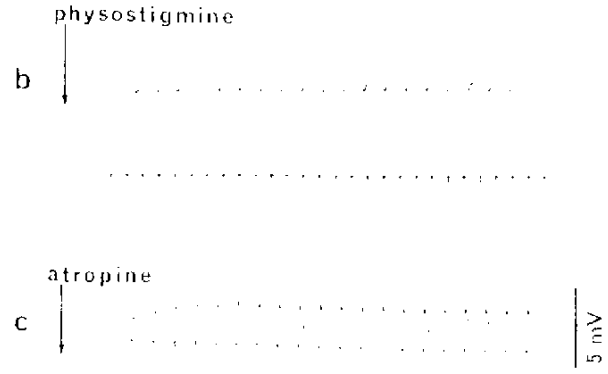

Fk. 6. Fllect of phssostigmine $15 \cdot 10 \mathrm{i}$ giml) on LJPs in the longifudinal muscke enoked by repotitive stimulation at $0.8 \mathrm{~Hz}$ of the intramural nenes. (a). Control: (b), at 10 min after physostigmine: (c), al 10 min after additive!y applied atropine (2. $10^{\circ} \mathrm{g}(\mathrm{ml})$. Upper trace in (a), (b) and (c), lime marker: lower trace, menbrane potential recording. Note the lack of change in the basal nembrane potential indicaled in the width between the time marker and the membrane polential recording.

the EJPs (6 experiments). The inhibitory elfect of physostigmine was found to he related to its well known ability to antagonize cholinesterase, since anticholinesterases other than physostigmine, such as neostigmine and DFP hat a similar inhibitory eflect on the EJPs and atropine $\left(10^{-1)}\right.$ giml) overcame the inhibition produced by these cholinesterase inhibitors. A typical experiment in the longitudinal musele is presented in Fig. 6.

Epinephrine and norepinephrine caused a contractite response of the longitudinal muscle associated with an increase in electrical activity after blockade of beta-adrenoceptors (unpublished obscrvation). Phentolamine $\left(10^{5} \mathrm{~g} / \mathrm{ml}\right)$ abolished the excitalory response due to activation of alpha-adrenoceptors to catecholamine, but did not aflect the EJPs. In the circular muscle, the catecholamines had no excitatory effect. Guancthidine, when added to the perfusion fluid to give a concentration of 1 to $5 \cdot 10^{5} \mathrm{~g} / \mathrm{ml}$, resulted in no detectable change in the junction potentials throughout the $3 \mathrm{hr}$ period ( 3 experiments). From these results, it is assumed that the EJPs are elicited by stimulation of neurons other than cholinergic and adrenergic neurons, and the motor transmission to the smooth muscle may be inhibited by cholinergic nerves 


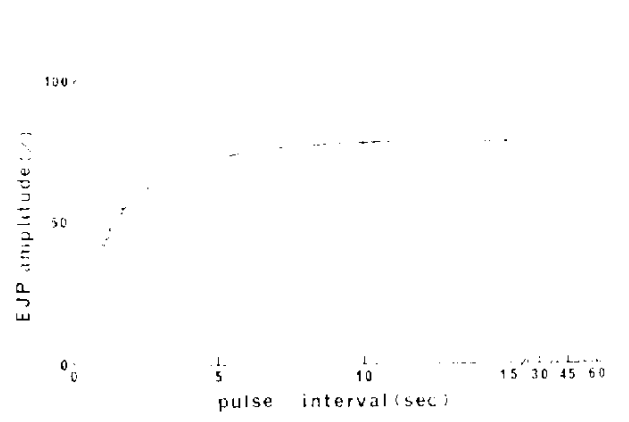

Fri. 7. Relationship between the pulse interal and the amplitude of the second EJP as a percentage of the first in the circular muscle. EJPs were evoked by stimulation with paired pulses at different pulse intervals of the intramural nerves. Each point represents the mean of three or six separate deterninations. The vertical hats represent the = S.t. for the last point the 'S.F. falls within the circle).
$100-$

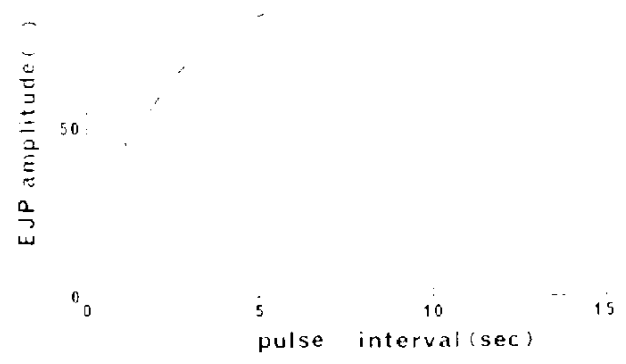

Fig. 8. Effects of atropine $\left(10^{-i} \mathrm{~g}\right.$ ml) on the relationship becween the pulse interval and the amplitude of the second EJP as a percentage of the first in the circular muscle. Circles, betore atropine: squares, at $10 \mathrm{~min}$ after atropine. Determinations in one and the same preparation.

Effects of atropine on the sudden depression of newromuscular transmixsion doring repetitive itimulation

The sudden depression of neuromuscular transmission in the circular muscle observed during repetitive stimulation was more closely examined by paired stimulus pulses with varied intervals. Results were expressed as the percent change in the amplitude of the sccond FIP from the amplitude of the first. Depression of the second EJP could be still seen at a pulse interval of $30 \mathrm{sec}$ as indicated in Fig. 7. Atropine produced a dose-dependent increase in the rate of abatement of the depression. Fig. 8 presents the relationships between the amplitude of the second EJP and the pulse interval before and after application of atropine $(10 \cdot \mathrm{g} / \mathrm{ml})$. At higher concentrations of atropine, the depression was no longer seen, instead the second EJP demonstrated a slight facilitation of the neuromuscular transmission. These observations also suggest that the depression of the motor neurotransmission is associated with stimulation of cholinergic neurons.

\section{Effects of physostigmine and atropine on membrane potential and menbrane resistance}

It is well known that acctylcholine activates the muscarinic receptors located in intestinal smooth muscie to reduce the membrane potential and membrane resistance by increasing the ion permeability. Drugs such as physostigmine inhibit cholinesterase and acetylcholint accumulates at the neuromuscular junction, thereby resulting in a decrease in the EJP amplitude. We then attempted to determine whether or not the post-junctional effect of acetylcholine contributes to the cholinergic inhibition of the EJPs. A few electrotonic potentials produced by passing hyperpolarizing current and several EJPs were alternatively recorded every 5 min from the same strip (see Methods). Fig. 9 shows an example of the effects of physostigmine $\left(10^{-6} \mathrm{~g} / \mathrm{ml}\right)$ on these potentials. Here, the EJPs were reduced to 


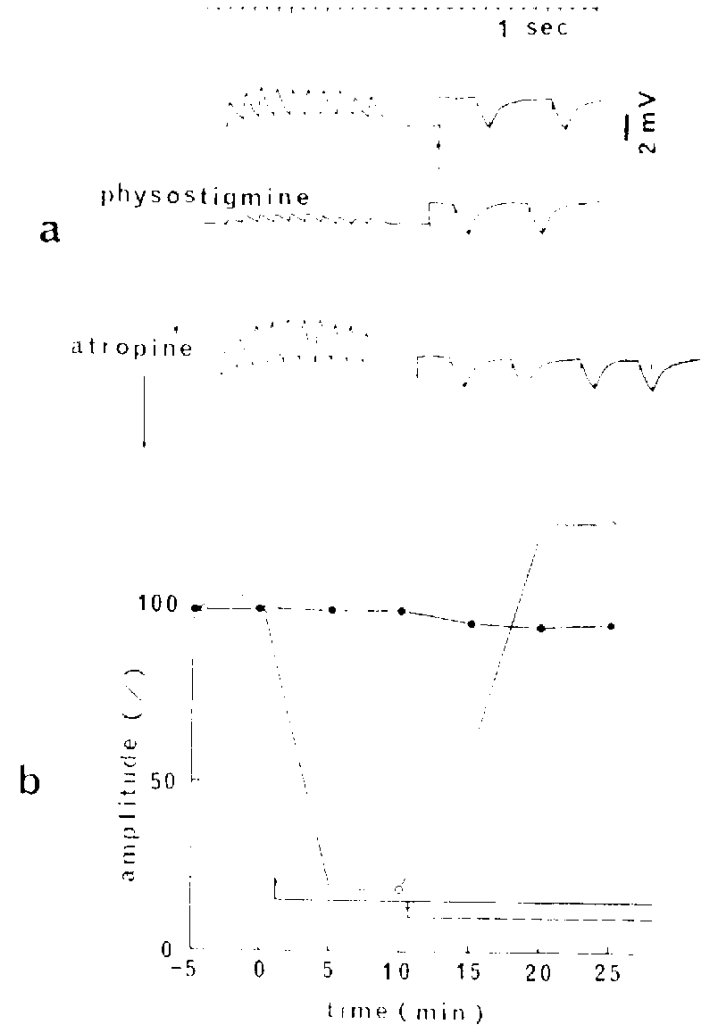

Fra. 9. Elfects of physustigmine $\left(10^{\circ} \mathrm{g} \mathrm{ml}\right)$ on EJPs and electrolonic potentials in the longitudinal muscle.
(a): Top trace, time marker: second, control: third, at 10 min after physostigmine: bottom, at $10 \mathrm{~min}$ after additively applied atropine $\left(10^{\circ} \mathrm{g} / \mathrm{ml}\right)$. At the upwarl arrow indicated, recording level is changed.
(b): A graph plotting the amplitude of the 5th EJPs (open circles) and the second electrotonic potentials (closed circles) croked by a short train of pulses. as percen- tages of the corresponding control, against time. The arrows indicate time and period of application of physostigmine (solid) and atropine (broken). Deter- minations in the same preparation as in (a).

about $20 \%$ of the control after 5 min exposure to physostigmine and remained inhibited in the presence of the drug, whereas the electrotonic potentials were not affected. Rapid recovery of the EJPs took place after addition of atropine $\left(10^{-5} \mathrm{~g} / \mathrm{ml}\right)$ and became about $25 \%$ larger than the control after $10 \mathrm{~min}$ exposure to atropine. The electrotonic potentials were reduced by less than $10 \%$ with atropine. Throughout this experiment, there was no detectable change in the resting membrane potential. This was confirmed in all five preparations. Thus, the physostigmine-induced reduction in EJP anplitude cannot be accounted for by a decrease in the membrane resistance and probably is the result of effects on the excitatory neurons.

\section{DISCUSSION}

The present experiments show the excitatory junction potentials (EJPs) evoked by 
stimutation of the intramural nerves of rectal smooth muscle of the chicken. Since the EJPs were not inhibited by the drugs that eliminate cholinergic and adrenergic activities, it seems likely that the neurons are neither cholinergic nor adrenergic. When tests are done to determine whether or not a certain drug can block neurally mediated responses, it is essential to ensure that there is a high concentration of the drug at the ncuromuscular junction. It seems likely that the junctional region could be exposed to the drugs used in the present experiments, since atropine and hyoscine appreciably potentiated the EJPs and the cholinesterase inhibitors reduced them.

Several observations on contractile responses of the chicken rectum to nerve stimulation indicated that this region of the intestine receives non-cholinergic, excitatory innervation $(1,5,6)$. The EJPs have several features in common with those of the contractions. Therefore, it is probable that the EJPS are electrical changes in the smooth muscle membrane in junctional transmission from neurons. the same type of which mediate the contractions.

The fatent period of the F.JPs is from one fifth to one tenth that of the cholinergic EJPs in the oesophagus $(7,8)$ and gizzard (9). Furthermore, this period was much shorter than that of EJPs recorded previously in mammalian intestines (10-13). If the latent period depends on the type of neuromuscular junctions occurring in the muscle (14), smooth muscle in the chicken rectum may be imnervated by single axons forming occasional close contact with smooth muscle cells as is the case in the vas deferens of the guinea-pig. It has been observed that electrical responses of intestinal smonth muscle to iontophoretically applied acetylcholine or carbachol have a latency longer than $0.1 \mathrm{sec}(15-17)$. Purves (16) and Bolton (17) suggested that the latency is not attributable to diffusion time and that it represents mainly the time required to produce the responses associated with activation of the muscarinic receptor. If such is indeed the case, then the extremcly short latencies of the I.JPs observed in the present experiments can be regarded as additional evidence that the motor neurons are not cholinergic in nature.

Hyperpolarizing junction potentials (IJPs) could be detected in records especially in those from the circular muscle and it appears that inhibitory neurons predominantly innervate the circular muscle layer. Although not systematically investigated, the failure of guanethidine and adrenoceptor-antagonists to block the IJPs suggests that the inhibitory neurons may be non-adrenergic in nature, presumably comparable to those previously demonstrated in the mammalian gastrointestinal tract $(12,1821)$.

The inhibitory effects of repetitive stimulation are clearly mediated through stimulation of cholinergic neurons, since this effect is abolished by atropine or hyoscine and is qualitatively minicked by the anticholinesterases. The inhibitory effects of the anticholinesterases on the EJPs were produced with little or no change in the membrane potential and membrane resistance. Thus the action of acetylcholine released from nerve endings may be mediated mainly through an eflect on the excitatory neurons rather than the direct effect on smooth muscle. Crema (22) stated that the postsynaptic receptors on inhibitory neurons in the cal colon are muscarinic. If the inhibitory neurons we observed in the chicken rectum also have muscarinic receptors. endogenously released acetylcholine would stimulate these 
neurons and cause an increase in relcase of the transmitter, resulting in a decrease in EJP amplitude. However, IIPS were evoked with little change in amplitude in the presence of atropine or hyoscine at a concentration sufficient to abolish depression of the motor neuromuscular transmission. Appreciable depression of the neuromuscular transmission could still be observed on the EJPs evoked by paired pulses with a pulse interval of $30 \mathrm{sec}$, while the IJP was not sustained for more than $5 \mathrm{sec}$. These results probably exclude the possibility that the depression is due to simultaneous elicitation of the I.JP.

Lindmar \& Muscholl (23) implied that a muscarinic mechanism inhibits the release of norepinephrine from poripheral adrenergic nerve fibers. Thus endogenously released acetylcholine may produce a diminution in the release of an unknown transmilter at the non-cholinergic nerve endings in at manner similar to the acetylcholine-mediated inhibition of norepinephrine release from adrenergic nerve endings.

\section{RHELRENCIS}

1) IAKLWAKI, I.. OHanit, H. and Okada, T.: Japall, J. Phamacol. 27, 105 (1977)

2) Ohasin, H., Nalto, K., Takevaki, T. avd Okada. T. Japan. J. Phamacol. 26, Suppl. $56 \mathrm{P}$ (1976)

3) Bülbrivg, E. and Burnsiock, G.: Brit. J. Phamacol. 15,611 (1960)

4) Bïlbring, F. and Tomita, T.: Proc. R. Soc. B. 172, 89 (1969)

5) Bartili, A.l. and Hassaiv, T.: Q. J/exp. Physiol. 56, 178 (1971)

6) BARILt:1, A.L..: Brit. J. Pharmacol. 51,549 (1974)

7) OHaSH, H. AM OHGA, A.: Natur, 216, 291 (1967)

8) Оhashi, H.: Japon. J. Phamacol. 21, 585 (1971)

9) Blintit, T.:J. Physiol. 204, 669 (1969)

10) Gillispí, J.S. AND MACK, A.L.: I. Physiol. 170, 19P (1964)

11) BeNNET1, M.R.: J. Physiol. 185, 132 (1966)

12) FURNLss, J.B.: J. Physiol, 205, $549(1969)$

(3) JTO, Y. and KuRlYama, H.: Japan. J. Physol. 21, 277 (1969)

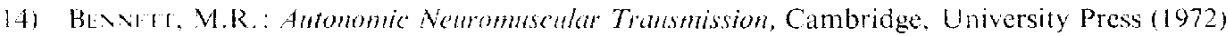

(5) Hidaka, T. and Klirtyaha, H.: /, gen. Physiol. 53, 471 (1969)

(6) PI.RVIS, R.D.: Brit. I. Pharmakal. 52, 77 (1974)

17) Bol.for. T.B.: Brit, f. Phamacol. 55, 304P (1975)

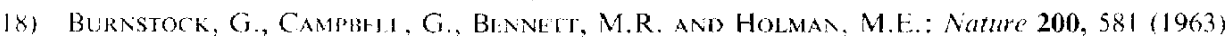

(9) BrNnetT. M.R., Burvstork, G. AnU HoIman, M.E.: J. Phyiol. 182, 541 (1966)

20) Kurmyana, H., Osa, T. and Tolda, N, J. Physiol. 191, 257 (1967)

21) BlaNi, L.. BIANCHI, C. AND CRI UA, A.: J. Phy:iol. 217, 259 (1971)

22) (rema, A.: Smooth Muscla, Fdited by Bïlbring, E., Brading, A.F., Jones, A.W. AND TOMis, T., Arnoki, London (1970)

23) LindMar, R.L. AND MUSCHOLl, E.: Brit. I. Pharmacol. 32. 280 (1968) 